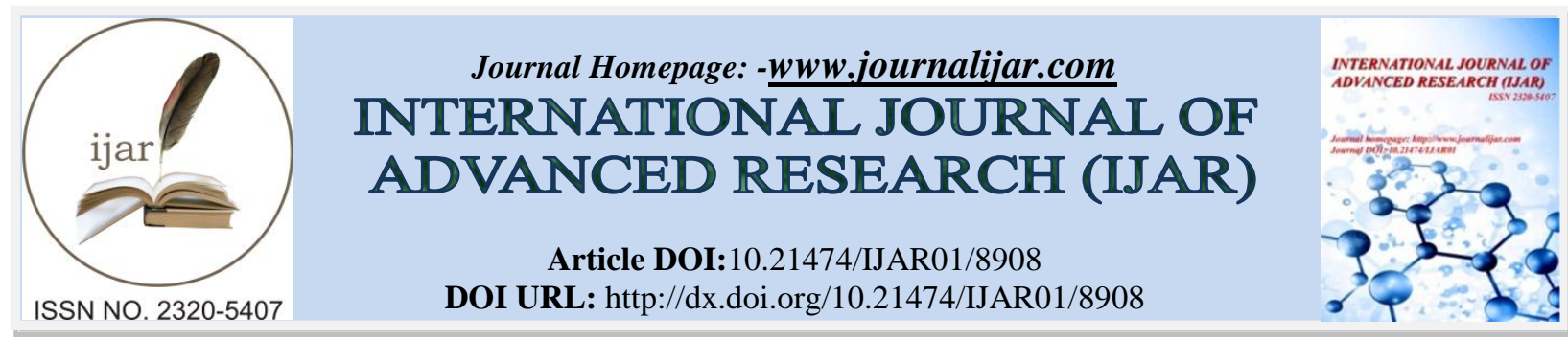

RESEARCH ARTICLE

\title{
BONE MARROW ASPIRATION STUDY AS A POINTER TO DIAGNOSIS OF GAUCHER'S DISEASE.
}

\section{Dr Savitri Singh ${ }^{1}$, Dr Jyotsna Madan ${ }^{1}$, Dr Devajit Nath ${ }^{1}$, Dr Nita Radha Krishnan ${ }^{2}$ Dr. Ratna Puri ${ }^{3}$ and Dr Neema Tiwari ${ }^{1}$. \\ 1. Dept. of Pathology, Superspeciality Pediatric Hospital And Post Gradute Teaching Institute. \\ 2. Dept of Pediatric Hemato-Oncology, Superspeciality Pediatric Hospital And Post Gradute Teaching Institute. \\ 3. Dept. of Genetic Medicine,Sir Gangaram Hospital.}

\section{Manuscript Info}

Manuscript History

Received: 12 February 2019

Final Accepted: 14 March 2019

Published: April 2019

Key words:-

Gauchers, bone, marrow, storage, disorders.

\section{Abstract}

Introduction:Gaucher's disease is an inherited, autosomal recessive storage disease of glucocerebroside due to a deficiency of glucocerebrosidase enzymes. It has an estimated global incidence of 1 : 40,000 to $1: 60,000$ live births. We present this to highlight the importance of bone marrow examination as an initial diagnostic modality providing an early pointer towards storage disorders, thus reducing the diagnostic delay and helping in early treatment initiation.

Method:(Case) We present a 3 year old Hindu boy born out of a non consanguineous marriage $\left(1^{\text {st }}\right.$ child) referred to special $\mathrm{OPD}(\mathrm{PHO})$ with complaints of pallor, recurrent infections and abdominal distension. He had hepatosplenomegaly and rest of the systems was within normal limit. His routine Peripheral blood examination showed a leucoerthroblastic picture with a reticulocyte count of $1.8 \%$. His glucocerebrosidase enzyme assay done from a private lab previously was inconclusive. A bone marrow examination was finally done and aspirate and biopsy revealed sheets of PAS positive gaucher cells. Imprint was not very informative.

Result:(Diagnosis) The genetic tests done in a outsourced lab using PCR with Gene ID 2629, revealed homozygous pLeu483 Pro pathogenic missense mutation which confirmed gauchers.

Conclusion:Our case highlights the importance of a meticulous bone marrow examination as a screening of storage disorders. Enzyme assays may be inconclusive in case of prior transfusion or if not performed in standard laboratories. However enzymatic study and genetic examination remain the gold standards for diagnosis of gauchers.

\section{Introduction:-}

Gaucher's disease is an inherited, autosomal recessive storage disease of glucocerebroside due to a deficiency of glucocerebrosidase enzymes. It is amongst the most frequently occurring lysosomal storage disorder in all ethnicities. Gauchers was first identified by Gaucher in 1882 and the storage of glucocerebroside was first recognized by Epstien in 1924. [1]The clinical manifestations and natural history of GD is highly heterogeneous with extreme geographic and ethnic variations. It has an estimated global incidence of 1: 40,000 to 1:60,000 live 
births [1]. As far as incidence of gaucher goes, most published literature is almost entirely focused on Caucasian patients [2]. Due to the tradition of consanguineous marriages in parts of the country, it seems likely that the frequency of Gaucher disease may be higher in India.[3]

The metabolic defect is deficiency of enzyme acid glucosidase (lysosomal glucocerebrosidase) due to biallelic mutations in $G B A$ gene that results in the accumulation of glucocerebroside in lysosomes, classically in tissue macrophages; other cell types involved in disease pathophysiology include immune cells, osteoblasts and hepatocytes [4]. Gaucher's disease has been divided into three classifications: Types 1, 2 and 3, based on the particular symptoms and course of the disease. [5] Type 1 is the most common and presents with pancyptopenia, hepatosplenogmegaly, and abnormalities is skeletal structure. The symptoms can appear at any time from infancy to old age. While Gaucher's disease is predominately an illness that manifests in infancy, case reports are showing that more of the geriatric population is being diagnosed with Gaucher's disease.

Various diagnostic modalities are available to asses' gaucher's including enzyme assays and genetic study. However bone marrow examination should be the first step towards diagnosing storage disorder rather than the expensive enzyme assay which is not available at every centre.

\section{Case Report}

A 3 year old Hindu boy born out of a non consanguineous marriage ( $1^{\text {st }}$ child) referred to special OPD(Pediatric Hemato-oncology unit) with complaints of pallor, recurrent infections and abdominal distension. His developmental history was normal. He has a history of transfusion at 1.5 years of age. On admission he was afebrile but had abscesses in the head and neck region. He had hepatosplenomegaly and rest of the systems were within normal limit. He was investigated for various causes including infections like HIV, Portal hypertension, hemolytic process and storage disorders.

His routine Peripheral blood examination showed a leucoertythroblastic picture with a reticulocyte count of $1.8 \%$.His LFT was normal, with negative direct coombs test,lieshman antibody IgG, HIV and a normal Osmotic fragility and HPLC. His glucocerebrosidase enzyme assay done from a private lab before admission in our hospital was inconclusive.Consent was taken and a bone marrow examination was finally done after ruling out other clinical entities. Imprint was not very informative and aspirate and biopsy revealed sheets of PAS positive gaucher cells. A culture of marrow for mycobacterium tuberculosis, rhodamine auramine and AFB staining were all negative.

A diagnosis of storage disorder based on marrow findings was made and for confirmation genetic studies were suggested. The genetic tests done in a outsourced lab using PCR on dried blood spot with Gene ID 2629, revealed homozygous pLeu483 Pro pathogenic missense mutation which confirmed gauchers.

\section{Discussion:-}

Gauchers disease is an autosomal recessive disease caused by accumulation of glucocerebroside /glycosylceramide in the retoculoendothelial cells in liver, spleen and bone marrow due to defect in lysosomal beta glucocerebrosidase enzyme. Gaucher disease is divided into 3 subtypes comprising of Type1(Chronic non neuropathic adult type),Type2(Acute non neuropathic type),Type3(Sub acute neuropathic, juvenile type) [6]

It carries increased risk for hematological malignancies. The glucerebrosidase gene is located on chromosome $1 \mathrm{q} 21$ and glucocerebroside is a component of the cell membrane. Glucocerebrosiadse enzyme helps in enzymatic breakdown of glucosylceramide into glucose and ceramide. Deficiency of this enzyme leads to accumulation of glucocerebroside in various organs. There is a first reported case in the literature of Gaucher's disease associated with a translocation between chromosomes 5 and 14. Such a translocation has also been reported in acute lymphoblastic leukemia.[7] Of more than 300 mutations seen in Gaucher disease, L444P, a pseudo gene sequence involved in GBA conversion, appears to be the most prevalent in India [5]. An important point to note is the elevated levels of glucosylceramide and glucosphingosine in neuronopathic diseases.[8]

Diagnosis of gauchers disease rests on demonstration of presence of Gauchers cells and in our case report we have highlighted the importance of bone marrow examination as first line investigation over expensive tests like enzyme assays in diagnosing storage disorders. It was seen in our case that the enzyme assay done in a private lab to rule out gauchers in the young child presenting with hepatosplenomegaly came out to be negative which delayed the diagnosis for months, while the bone marrow aspirate raised a suspicion of gauchers which was later on confirmed 
by positive genetic studies. An early bone marrow aspiration biopsy could have avoided the delay in diagnosis and initiating treatment.

Gaucher cells are pale, round polyhedral, 20-40 microns with eccentric nuclei with variable chromatin content and ample cytoplasm which is fine and wavy like crumpled tissue paper (representing accumulation of glucocerebrosides).[9]The cytoplasm shows strong PAS positivity. Mimicking these cells are the Pseudo gaucher cells commonly found in Leukemias, MDS and CDA etc.

Hence these lesions are differentiated by presence of neoplastic cells like blasts in leukemias,or dysplasia in the hemopoietic lineage like in MDS, erythroid hyperplasia, with erythroid megaloblastosis to normoblastic changes and dysplasia in CDA.[10]

Complications of gauchers disease include hypersplenism and pancytopenia,splenic rupture, bleeding diathesis due to thrombocytopenia and acquired coagulopathy, fractures and collapsed vertebral bodies, avascular osteonecrosis, chronic bone pain and bone crisis, hepatic fibrosis, portal hypertension hepatopulmonary syndrome, hematological malignancies - multiple myeloma, hepatocellular carcinoma, Parkinson's disease with Lewy body dementia, Progressive neurodegenerative disease in Gaucher disease type 2 and 3[11]

In India Gaucher Disease Task Force was formed under the aegis of the Society for Indian Academy of Medical Genetics. The guidelines were finalized in December 2016 at the annual meeting of the Indian Academy of Medical Genetics. Gauchers disease has variable manifestations and is diagnosed late in most of the cases. Leukocyte acid glucosidase activity is mandatory for establishing the diagnosis of Gaucher disease; molecular testing can help identify patients at risk of neuronopathic disease. However our case report proves that going for a bone marrow examination before expensive enzymatic tests proves beneficial for the patient and points towards an early diagnosis. Enzyme replacement therapy for type 1 and type 3 Gaucher disease is the standard of care. Best outcomes are achieved by early initiation of therapy before onset of irreversible complications. The recommendations herein are for diagnosis, for initiation of therapy, therapeutic goals, monitoring and follow up of patients[12]

In our case the child was counseled for close follow up and effort to initiate enzyme replacement therapy is underway .

\section{Conclusion:-}

Gaucher's is under diagnosed in India due to limitations in diagnostic resources for genetic testing and evaluation. However hematologists need to be aware of gauchers as a differential in patients with symptoms as there are modalities for an early diagnosis and initiation of treatment. Our case highlights the importance of a meticulous bone marrow examination with other sensitive and specific tests like the enzyme assay and gene studies for storage disorders. However at times enzyme assays may come out false negative, as in our case, if not performed in standardized labs under standardized conditions. In such cases a bone marrow examination helps as a pointer for diagnosis of a storage disorder. Enzymatic assay or genetic studies remain gold standard for confirmation of the disease. Hence through this case report we have tried to highlight the importance of initial bone marrow examination as a pointer for further workup for storage disorders as marrow examination is an invasive yet affordable technique done easily at any set up with some expertise.

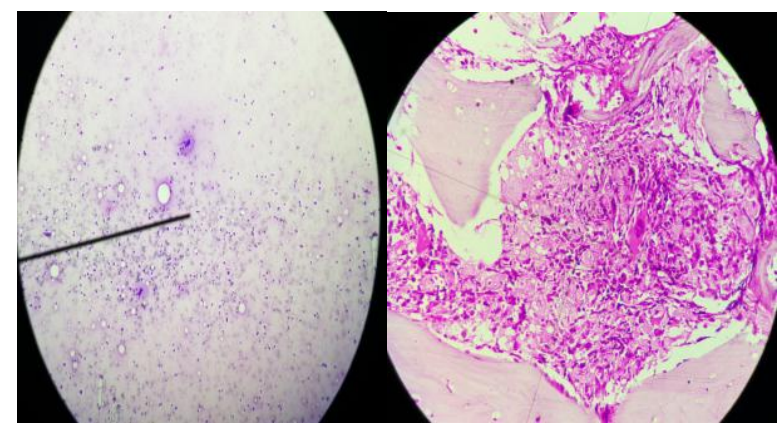

Fig1:-Low power (10x) showing bone marrow aspirate with histiocyte Fig3:-Low power(10x) bone marrow biopsy showing gaucher cells. 


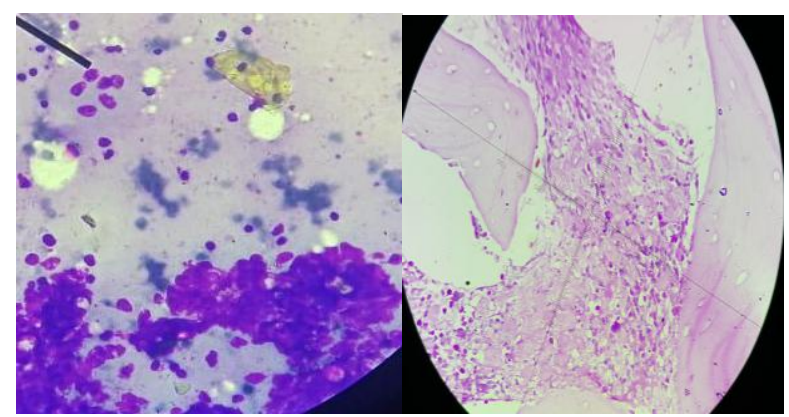

Fig2:-Multinucleate gaucher cell in aspirate

Fig4:-Low power(10x) Bone marrow biopsy showing PAS positive glucocerebroside in gaucher cells.

\section{Reference:-}

1. Belmatoug N, Caubel I, Strinemann J, Billette de Villemeur T. Gaucher's disease. J Soc Biol. 2002;196:141-9. Rosenbloom BE, Weinreb NJ, Zimran A, Kacena KA, Charrow J, Ward E. Gaucher disease and cancer incidence: a study from the Gaucher Registry. Blood. 2005; 105:4569-72.

2. de Fost M, Vom Dahl S, Weverling GJ, Brill N, Brett S, Haussinger D, Hollak CE. Increased incidence of cancer in adult Gaucher disease in Western Europe. Blood Cells Mol Dis. 2006;36:53-8.

3. HJ Mankin, CA Trahan, NA Barnett, J Laughead, CM Bove, GM Pastores. A questionnaire study for 128 patients with Gaucher disease.Clinical Genetics 2006;69:209-17.

4. Troy K, Cuttner J, Reilly M, Grabowski G, Desnick R. Tartrate-resistant acid phosphatase staining of monocytes in Gaucher disease. Am J Hematol. 1985;19:237-44.

5. Shiran A, Brenner B, Laor A, Tatarsky I. Increased risk of cancer in patients with Gaucher disease. Cancer. 1993;72:219-24.

Bernard OA, Busson-LeConiat M, Ballerini P, Mauchauffé M, Della Valle V, Monni R, Nguyen Kahc F, Mercher T, Penard-Lachronique V, Pasturaud P, Gressin L, Heilig R, Daniel MT, Lessard M, Berger R. A new recurrent and specific translocation, $t(5 ; 14)(\mathrm{q} 35, \mathrm{q} 32)$ is associated with expression of the HOX11L2 gene in T-acute lymphoblastic leukemia. Leukemia 2001;15:1495-1504.

6. Haran MZ, Feldberg E, Berrebi A. Incidental diagnosis of Gaucher's disease in an elderly patient with lymphoma. Leuk Lymphoma. 2001;40:445-9. Hogan TF, Koss W, Murgo AJ, Amato RS, Fontana JA, VanScoy FL. Acute lymphoblastic leukemia with chromosomal 5; 14 translocation and hypereosinophilia: case report and literature review. J Clin Oncol. 1987;5:382-90.

7. Ratna Dua Puri ${ }^{1}$, Seema Kapoor ${ }^{2}$, Priya S Kishnani ${ }^{3}$, Ashwin Dalal ${ }^{4}$, Neerja Gupta ${ }^{5}$, Mamta Muranjan ${ }^{6}$, Shubha R Phadke, Anupam Sachdeva ${ }^{7}$, Ishwar C Verma ${ }^{7}$ and Pramod K Mistry ${ }^{9}$. Diagnosis and Management of Gaucher Disease in India - Consensus Guidelines of the Gaucher Disease Task Force of the Society for Indian Academy of Medical Genetics and the Indian Academy of Pediatrics. https://www.indianpediatrics.net/feb2018/feb-143-153.htm. 